\title{
Exploring the Correlation Between Personality and Occupational Variables of the Nurse and Between Attitudes and Behavioral Intentions Towards Euthanasia
}

\author{
Liran Penn ${ }^{1}$ and Nili Tabak ${ }^{2, *}$ \\ ${ }^{1}$ Emek Medical Center, ${ }^{2}$ Ethics and Law Unit, Department of Nursing, School of Health Professions, Faculty of \\ Medicine, Tel Aviv University, Tel Aviv, Israel
}

\begin{abstract}
This research focuses on the factors that influence nurse' stands towards mercy killing and on the relationship between these factors and the intention of action among nurses in hospitals. Within this research, the theory of Reasoned Action of Fishbein \& Ajzen is used. The purpose of this theory is to understand the individual's behavior and to predict it. With it, there is an attempt to explain the process of an individual's decision-making concerning their behavior. Using convenient sampling, several questionnaires were filled by 100 hospitals nurses. The research hypothesises relate to the relationship between variables and nurses' view towards mercy killing. The hypotheses have also related to the relationship between nurses' stand and behavioral intention, and the factors that influence the stance and the behavior intention. Finding showed that the extent of religiousness and level of academic education is a good predictor of attitudes towards euthanasia among nurses. Also, that some Situational variables such as - the kind of disease, the patient's age and the relationship between the patient and the caregiver have influence on attitudes towards euthanasia and behavioral intention.
\end{abstract}

\section{INTRODUCTION}

Nurses - by the virtue of their duty to supply care for patients towards the end of their life, confront a situation in which pleas are raised by patients and their family members to help them end their life. According to the literature it seems as if nurses are those who are asked to be involved in an act that is intentionally inflict to the patient's death, either by the patient himself or by his family members and the medical staff $[1,2]$.

In Israel, the law of "the dying patient" was enacted recently (2007) [3], and it concerns the instruction of providing care to patients on their last days. The rise in discussing this issue in the national level and also in the international one compelling nurses to examine their attitudes towards euthanasia in the individual level and as nurses as well. In the world literature it was found, that Jewish health workers tend to support euthanasia in all its forms more than their counterparts the Catholic and Protestant believers [4-7]. In Israel, and especially in regard to observants, there is an additional binding law system - the Jewish religious laws (Halacha). The Jewish religion is guided by the concept of life sacredness and human dignity, from which stems the high virtue of life, as man was made in the image of god [8]. World literature found that variables such as: religious ascription, extent of religiousness, age, education, seniority in work, ethnicity and fear of death and the process of dying are among the variables influencing the nurses' attitudes towards euthanasia. Because this topic was hardly explored in Israel, this research focuses on the factors influencing

*Address correspondence to this author at the Ethics and Law Unit, Department of Nursing, School of Health Professions, Faculty of Medicine, Tel Aviv University, Tel Aviv, Israel; Tel: 972-3-6409660;

E-mail: ntabak@post.tau.ac.il nurses' attitudes towards euthanasia and the correlation between the aforementioned factors and the actual behavioral intention among nurses in Israeli hospitals. In this framework, the theory of Ajzen \& Fisbein of 1975 [9], which is called the theory of reasoned behavior, may be used in order to better understand and predict individuals' behavior.

\section{LITERATURE REVIEW}

According to Henderson [10], one of the nurse's duties is to bring about patient's peaceful death. On the practical level sometimes the four basic bio-ethical principles, which were adopted from the Hippocratic oath, contradict each other, albeit their meaning has to be taken into account in any analysis of a concrete situation [11]. In the Israeli ethical code of nurses of 1994 to which nurses are obliged, there is a reference to human dignity in matters concerning life or death, and the act provides that: "the patient has a right to die in dignity, while protecting his virtues and independence.

As a result of the situation complexity and the clash between principles, the theoretic framework being chosen for the present research was the theory of reasoned action $[9,12]$. The aim of this theory is to understand the individual's behavior and to predict it, in our case - nurse's behavior in a situation of euthanasia.

The theory of reasoned action: This theory constitutes a wide theoretical framework combining most human behaviors through a small number of research concepts, and it can be empirically examined as well as supply a systematic approach to behavior research in different fields. In the practical aspect the theory may be used as a diagnostic tool for identifying the factors distinguishing between different types of people and the variation of their behaviors in identical situations. 
According to Fisbein \& Ajzen, intention to behavior is to be distinguished from the actual behavior, while the individual's intention to carry out (or not to carry out) a particular behavior is the factor determining his behavior, that is to say, the principle predictor of behavior is the behavioral intention. Behavioral intention is defined as the subjective probability that an individual would carry out a specific behavior. If we were able to identify the behavioral intention, we could also predict the expected behavior. This intention is the result of two factors. The first factor is the attitude towards a behavior and the second one is the subjective norm.

Attitude - the individual's positive or negative appreciation of carrying out the behavior. The attitude refers to the individual's judgment, if carrying out the behavior is a good or a bad thing. The attitude is influenced by the person's system of beliefs, his experiences and feelings.

Subjective norm - Subjective norm represents the social element reflecting the social point of view, that is to say understanding the individual and the social pressures imposed on him in regard to the goal behavior. A person believing that most of his significant others think that he has to carry out a particular behavior would perceive the social pressure as supporting the carrying out of such a behavior. Attitudes towards behavior are a function of behavioral belief [12]. Behavioral belief represents the general information the individual has in regard to the expected results of a behavior. Through the processes of attaining information as well as of information processing and inferring, the individual shapes some of his beliefs, which, would in their turn, design his behavioral attitude and his subjective norm.

In the research carried out by Savage, Cullen. Krichof, Pugh \& Formen [13] the theory of Fisbein \& Ajzen was used in order to predict nurses' behavior. It was found that subjective norms, such as: medical instruction, for example, was a factor that influenced the behavior more than nurse's attitudes. In the literature review there were no researchers found that were using the theory of reasoned action for examining attitudes and behavioral intentions of nurses towards euthanasia among adults.

\section{Euthanasia - Ethical Dilemmas}

In the dilemma of life prolonging in contrast to the question of the quality of life, the autonomy of patients is to be a central topic. Autonomy or the right to selfdetermination consist a very basic and principal ethical problem. The patient has the right to receive a due care and refuse treatments [14]. The supporters of the paternalistic approach agree to the imposing of partial restriction of the individual's freedom, including waiving the need to get the patient's explicit consent, on the basis of the argument that it avoids damage to the patient or do well for him. On the other hand, the autonomy supporters oblige a decision making by the patient's family members or by the court, as patient's representatives, in such a case that the patient is not able to autonomic thinking [15]. According to Kerridge and Kennth [16], if we assist a terminal patient, we should also respect the will of a patient who is not terminally ill but who is suffering from pain or a chronic disease, or who is found in a situation of loneliness and depression. It is common that one of the most necessary and tough criteria in this topic is that the patient would be terminally ill. Why this criterion among all others was chosen? Such questions raise the awareness to the danger of a slippery slope.

The slippery slope is a situation in which, if we allow one particular behavior, which looks right and which is morally appropriate, there is a reasonable fear that this permission would bring about another behavior, which is evidently immoral or that is morally inappropriate [17]. There is a fear that we very soon get into a situation according to which a person would decide that a particular kind of life worth more than other kinds.

\section{Attitudes Towards Euthanasia}

In the context of nurses' attitudes towards euthanasia the data are quiet different from one research to another. Kuhse $\&$ Singer [18] found that 75 per cent of the nurses believed that it is necessary that euthanasia would become legal. In contrast, in another research, 23 per cent of the participants believed that from a moral point of view voluntary active euthanasia is right. However, actually only 14 per cent were ready to take part in an active euthanasia if such an act would have been legal [19].

\section{Variables Influencing Nurses' Attitudes Towards Euthanasia}

\section{Extent of Religiousness}

Extent of religiousness was found as a good predicting tool of the attitudes towards euthanasia among nurses. Mursgave, Margalith \& Goldsmidt [20] found that the more the nurse defines himself as religious, the less he would tend to support the physician assisted dying. In a survey being carried out in Israel in two medical centers, it was found that in the religious center only 34 per cent of the physicians supported active euthanasia, while 53 per cent of the physicians in the non-religious center supported it [21].

\section{The Fear of Death and of the Process of Dying}

The fear of death was found as one of the best predictors of students' attitudes towards life prolonging treatments [22]. Gog \& Williams [23] it was found that there is a correlation between nurses' age and their anxiety of death. Nurses' extent of anxiety of death decreased as the age of them increased and the more they had accumulated experience in treating terminally ill patients. Tomer \& Elison [24] argued that anxiety of death is related to the extent of exposure to it.

\section{Variable Influencing the Attitudes Towards Euthanasia} and Behavioral Intention

\section{The Relationship Between the Patient and Caregiver}

The fact of previous existing relationship between the caregiver and the patient was found as influencing the caregiver's attitudes and behavioral intentions towards euthanasia. Research found that when there was previous relationship between the caregiver and the patient, more nurses supported the physician assisted dying and more of them were ready to attend as well as to take part in a physician assisted dying, at the time of carrying out the assisting dying, in contrast to a situation in which a treatment that was not known to the nurse was involved [7,20]. 


\section{Variables Influencing Behavioral Intentions}

\section{The Perception of A Subjective Norm}

The patient's will - Kowalski [25] found that 67 per cent of the nurses' supported the becoming physician assisted dying legal, and they based it on the argument of patient's autonomy.

Medical instruction - in an American research, it was found that 16 per cent of nurses indicated that they were ready to inject a deadly drug according to a medical instruction when to a competent patient who asked for it [7]. In a research by Savage, Cullen, Krichof, Pugh \& Formen [13], which tested nurses' reactions towards the command of D.N.R. (not to carry out resuscitation) in premature babies, it was found that subjective norms, such as medical instruction, for example, were a more influencing factor on behavior than nurse's attitudes. Nurses tended to deny their personal attitude and acted according to medical instruction.

The wish of family members - 58.82 per cent of the nurses who supported active euthanasia said that they were ready to act accordingly, but only after getting the consent of the patient's family members [26].

\section{Correlation Between Attitudes Towards Euthanasia and Behavioral Intention}

Research shows that there is a gap between attitudes towards euthanasia and behavioral intentions. A Japanese research found that 23 per cent of the nurses thought that active euthanasia would be accepted under some particular circumstances but only 14 per cent responded that they were actually ready to participate in it, if such an act would have been legal [19]. In a different western research it was found that 60 per cent of the supporters of an active euthanasia agreed to take part in it, and also that 10 per cent of it's opponents agreed to take part in such an act. The arguments on which participants' agreement was based were a medical instruction and patient's right to make choice [26]. Richardson [27] found that 53 per cent agreed that terminally ill patients have to be permitted to put an end to their life. From this rate of 53 per cent - 55 per cent did not agree to take part in active euthanasia, even if such an act was legal and was asked for by the patient.

\section{THE RESEARCH MODEL}

The correlation between nurse's variables to attitudes and behavioral intentions towards euthanasia, based on the theory of reasoned action and the literature that was reviewed:

The research's groups of hypotheses:

1. Socio demographic variables - extent of religiousness would be related to the attitudes towards euthanasia. Religious nurses would have more negative attitude towards euthanasia.

2. Professional variables - level of education - would be related to attitudes towards euthanasia. We expect to see differences in the attitudes of people with different education levels.
3. Situational variables such as - the kind of disease, the patient's age and the relationship between the patient and the caregiver would influence the attitudes towards euthanasia and behavioral intention. We expect to see a correlation between the attitude and the behavioral intention in regard to patients' age, correlation between the attitude and the behavioral intention among patients who suffer from different kinds of diseases and correlation between the attitude and the behavioral intention with different levels of relationships between the patient and the caregiver.

4. We expect to see a correlation between the attitude and behavioral intention. The more the attitude towards euthanasia would be positive, the more the behavioral intention would be positive too.

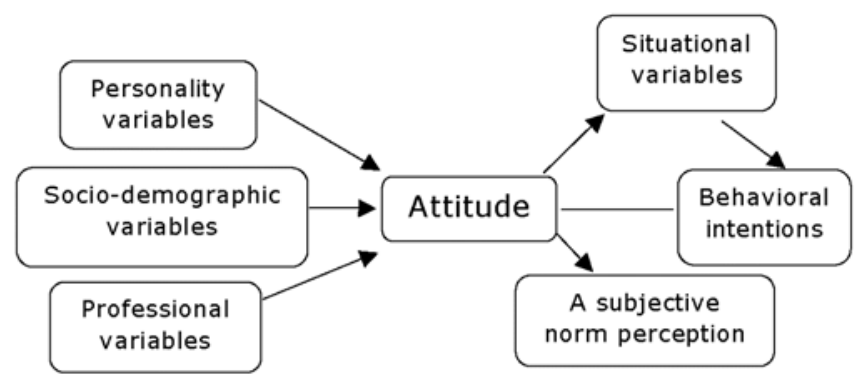

Fig. (1).

\section{RESEARCH MATERIALS AND METHODOLOGY}

The sample - a convenience sample included 100 nurses, some worked in the surgical wards (45) and some worked in internal medicine ward (55), in a northern hospital in Israel. The sample included practical nurses as well as qualified and qualified plus first and second degrees nurses.

The research tools - a questionnaire consisted of three parts was used. The questionnaire was fully constructed by the researcher, and was based on existing questionnaires as well as on pertinent questions that were added by the researcher.

A. The socio demographic questionnaire - This questionnaire included the following variables: sex, age, marital status, number of children, county of birth, parents' country birth, professional education, number of years of seniority, the ward, role in the ward and religion.

B. A questionnaire for testing fear of death and of dying This questionnaire included 14 questions designed to examine the extent of anxiety of death and of dying. This questionnaire was taken from the work of Carmel \& Mutran [28]. The possible responses were according to the 5-point Likert scale. Factor analysis was carried out on the questionnaire by Carmel and two factors were found. The first factor referred to the extent of anxiety of dying. The internal reliability (Cronbach's alpha) was 0.85 (in the original research). The second factor referred to the extent of anxiety of death. The internal reliability that was found (Cronbach's alpha) was .81 (in the original research).

C. Questionnaire of attitudes towards euthanasia:

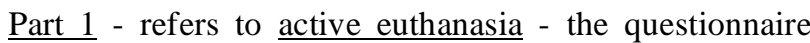
has been constructed by the researcher. It includes twelve 
case studies. The case studies described people in different ages, which suffered from different kinds of diseases and who also had different levels of relationship with their caregiver. The people who participated were asked about the carrying out of euthanasia. In the rest of the story the physician entered the room for carrying out the euthanasia. After every story two questions were asked. The first question referred to the participant's attitudes towards euthanasia (consent to the physician's act). The second question referred to the behavioral intention, and it was measured on 3-point Likert scale ranging from 1 - 'ready to act' (to be the one who really gives the patient the drug), to 2 - 'ready to attend but not to act' and to 3 - 'neither ready to attend nor to act'.

$\underline{\text { Part } 2}$ - refers to subjective norm and was constructed by the researcher. It was consisted of six questions that checked the influence of different variables on the participant's readiness to take active part in euthanasia.

$\underline{\text { Part } 3}$ - refers to passive euthanasia, and it was consisted of four possible situation descriptions, when after every description three questions were presented. The questions referred to the attitudes towards life prolonging, through artificial feeding or connecting to a breathing machine or carrying out resuscitation. These questions were taken from Zeidenberg's research [29], which checked nurses' attitudes in regard to life prolonging of terminally ill patients. The internal reliability (Cronbach's alpha) was .88 (in the original research).

Part 4 - few open questions, which referred to the different aspects of euthanasia, were also included. The questionnaire was reviewed and validated by several Judges. It was given to some nurses who's familiar with the field of ethics and administration and was also corrected according to their remarks. These nurses were not part of the research sample.

Analysis: all questioners were handed to the nurses in the sample by the researcher and were collected after completion. All the data was processed using SPSS program. Statistical tests to study the research's hypotheses included Pirson and Spearman correlation, ANOVA variance analysis model, and $\mathrm{T}$ tests, when suitable.

\section{RESULTS}

The First Group of Hypotheses: Socio Demographic Variables - Extent of Religiousness

Examining the hypothesis was done through ANOVA variance analysis model.

Tests' findings showed that there are no significant differences in relation to attitudes towards euthanasia among respondents with different levels of religiousness $(\mathrm{F}(2$, 97) $=8.869 ; \mathrm{p}>0.05)$. However when grouping observant and religious respondents and comparing this new group to secular respondents using $\mathrm{T}$ test $(\mathrm{t}(98)=-2.303 ; \mathrm{p}<0.05)$, significant differences were found between secular respondents $(3.06 \pm 1.20)$ and between observant and religious respondents $(3.66 \pm 1.28)$. In other words, the hypothesis that religious nurses would have more negative attitudes towards euthanasia was supported.

\section{The Second Group of Hypotheses: Professional Variables -} Level of Education

Examining the hypothesis in regard to the variable of the level of education was done through ANOVA model of variance analysis.

The findings show that there were no significant differences in attitudes towards euthanasia scores between participants as a result of their division into four education levels (MA, BA, qualified and not qualified), but in contrast, that there were significant differences when the participants were divided into two groups (academic and non-academic) $(\mathrm{t}(97)=2.124 ; \mathrm{p}>0.05)$. The academic respondents had more positive attitudes towards euthanasia in comparison with their counterparts the non-academic respondents. Moreover there was a significant and high (Spearman) correlation between nurses' education and their attitudes towards euthanasia $(r s=0.283 ; p>0.01)$. The higher nurses' education was the more their attitudes were positive, and vice versa. Thus the first hypothesis of the second group of hypotheses was supported.

Moreover, a significant difference was found $(F(3$, $95)=2.776 ; p>0.05$ ) in behavioral intentions between respondents in the different education levels. Practical and qualified nurses were found with negative behavioral intention in contrast to academic nurses with B.A. and with M.A degrees. When nurses were divided into the main education groups (academic and non academic), significant differences were found $(t(97)=2.634 ; p>0.05)$ between the groups. So, education levels were correlated positively to behavioral intentions ( $r s=0.316 ; p>0.01)$. Moreover, significant differences were found in the scores of anxiety of dying between respondents with different education levels $(F(3,95)=2.968$; $\mathrm{p}>0.05)$.

The Third Group of Hypotheses: Situational Variables the Kind of Disease, the Patient's Age and the Relationship Between the Patient and the Caregiver

The third group of hypotheses examined the influence of different situations, such as the kind of disease, the patient's age and the relationship between the patient and the caregiver and between attitudes towards euthanasia and behavioral intentions. Attitudes towards euthanasia, which were conditioned by the patient's age, his disease and the relationship between the patient and caregiver was found by calculating the mean of responses to the pertinent items out of the questions in the section of attitudes towards euthanasia and of behavioral intentions.

The findings of Table $\mathbf{2}$ demonstrate that there are significant correlations between attitudes towards euthanasia that were conditioned by age and between behavioral intentions that were conditioned by it too. The strength of correlations ranged between 0.690 and 0.796 .

There was a significant positive correlation between nurses' attitudes towards euthanasia of young people and between behavioral intentions towards young people $(\mathrm{r}=0.796 ; \mathrm{p}<0.01)$. The more nurses' attitudes towards euthanasia of young people are positive, the more positive their behavioral intentions would be and vice versa. Similarly, there was a significant positive correlation found between nurses' attitudes towards euthanasia of old people 
Table 1. Matrix of Correlations (Pearson) between Situational Variables and Attitudes Towards Euthanasia

\begin{tabular}{|c|c|c|c|c|c|c|c|c|}
\hline 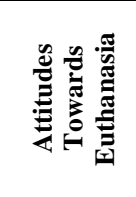 & 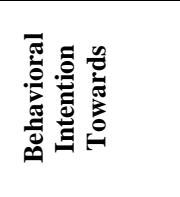 & 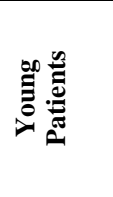 & 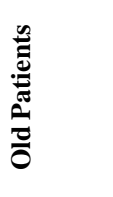 & 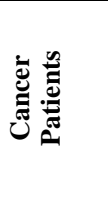 & 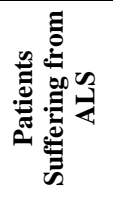 & 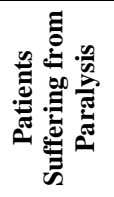 & 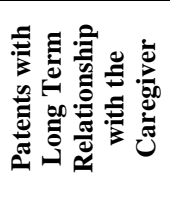 & 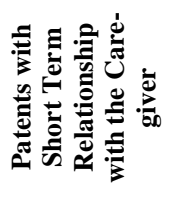 \\
\hline \multicolumn{2}{|c|}{ Young patients } & $.796(*)$ & $.690(*)$ & $.730(*)$ & $.739(*)$ & $.716(*)$ & $.747(*)$ & $.753(*)$ \\
\hline \multicolumn{2}{|c|}{ Old patients } & $.711(*)$ & $.753(*)$ & $.755(*)$ & $.693(*)$ & $.709(*)$ & $.727(*)$ & $.756(*)$ \\
\hline \multicolumn{2}{|c|}{ Cancer patients } & $.738(*)$ & $.724(*)$ & $.791(*)$ & $.700(*)$ & $.658(*)$ & $.734(*)$ & $.744(*)$ \\
\hline \multicolumn{2}{|c|}{$\begin{array}{l}\text { Patients suffering from amyotrophic } \\
\text { lateral sclerosis (ALS) }\end{array}$} & $.752(*)$ & $.716(*)$ & $.718(*)$ & $.747(*)$ & $.697(*)$ & $.742(*)$ & $.742(*)$ \\
\hline \multicolumn{2}{|c|}{ Patients suffering from paralysis $* * *$} & $.752(*)$ & $.710(*)$ & $.704(*)$ & $.681(*)$ & $.766(*)$ & $.719(*)$ & $.760(*)$ \\
\hline \multicolumn{2}{|c|}{$\begin{array}{l}\text { Patents with long term relationship } \\
\text { with the caregiver }\end{array}$} & $.760(*)$ & $.729(*)$ & $.736(*)$ & $.737(*)$ & $.720(*)$ & $.768(*)$ & $.737(*)$ \\
\hline \multicolumn{2}{|c|}{$\begin{array}{l}\text { Patents with short term relationship } \\
\text { with the caregiver }\end{array}$} & $.760(*)$ & $.728(*)$ & $.764(*)$ & $.704(*)$ & $.719(*)$ & $.719(*)$ & $.786(*)$ \\
\hline
\end{tabular}

$* p<.0 .01$.

***The phrase 'patients who suffer from paralysis' means patients as a result of an accident.

and between behavioral intentions towards old people $(\mathrm{r}=0.753 ; \mathrm{p}<0.01)$.

There were significant correlations found between attitudes towards euthanasia, that is to say, attitudes conditioned by disease and behavior intentions conditioned by disease. The strengths of correlations ranged between 0.658 and 0.791 . There was a significant positive correlation between nurses' attitudes towards euthanasia of cancer patients and between behavioral intentions towards these patients $(\mathrm{r}=0.791 ; \mathrm{p}<0.01)$. Similarly, there was a significant positive correlation found between nurses' attitudes towards euthanasia of patients who suffered from amyotrophic lateral sclerosis (ALS) and between behavioral intentions towards them $(r=0.747 ; p<0.01)$.

Moreover, significant correlations were found between attitudes towards euthanasia that is to say between the attitudes that were conditioned by the relationship between the patient and the caregiver and between behavioral intentions that were conditioned by the relationship between the two. The strengths of correlations ranged between 0.719 and 0.786. Significant positive correlation was found between nurses' attitudes towards euthanasia of patients with whom long-term relationship was existed and between behavioral intentions towards them $(r=0.768 ; \mathrm{p}<0.01)$. Thus, the fourth hypotheses group was fully supported.

In the findings analysis there were significant differences found between euthanasia of young patients and between attitudes towards euthanasia of old patients $(t(99)=3.070$; $\mathrm{p}<0.01)$. The findings demonstrate higher mean scores of attitudes towards euthanasia of old patents (3.19). In other words, the staff's attitudes towards euthanasia of old patients were more positive or resolute in comparison with attitudes towards euthanasia of young patients (3.36).

Another significant difference was found between attitudes towards euthanasia, with patient with whom there was long-term relationship in comparison with patient with whom there was short-term relationship $(t(99)=-3.963$; $\mathrm{p}<0.001)$. Thus, the positive attitudes towards euthanasia were strengthening on by Long-term relationship (3.18) in comparison with short-term relationship (3.36).

Another significant difference was found between attitudes towards euthanasia of patients suffering from amyotrophic lateral sclerosis (ALS) and cancer patients in comparison with patients suffering from paralysis $(\mathrm{t}(99)=-$ $1.869 ; \mathrm{p}<0.001)$. Attitudes towards euthanasia of patients suffering from amyotrophic lateral sclerosis (ALS) and cancer patients were found more positive (3.23) in comparison with the attitudes found towards euthanasia of patients suffering from paralysis (3.33). Moreover, significant differences were found between behavioral intentions towards young patients and between behavioral intentions towards old patients $(\mathrm{t}(99)=3.024 ; \mathrm{p}<0.01)$.

\section{The Forth Group of Hypotheses: Correlation Between Attitude and Behavioral Intention}

We assumed that there would be a positive correlation between attitudes and behavioral intention. A significant negative correlation was found between attitudes towards euthanasia and behavioral intention $(r=0.783$; $p<0.01)$, which means that attitudes towards euthanasia may predict 62 per cent of the total behavior intentions. Thus, the fifth hypothesis was supported.

\section{DISCUSSION}

The aim of this work was to investigate the correlation between nurses' personality and their professional variables and between attitudes and behavior intentions towards euthanasia.

In the literature a finding being demonstrated in many researches was that the extent of religiousness is a good predictor of attitudes towards euthanasia among nurses and other health workers from other disciplines [20, 21, 30]. In the present research the rate of respondents who considered themselves religious was only 4 per cent in contrast to a rate of 66 per cent of them who considered themselves secular and 30 per cent as observant. It is possible that this datum 
explains the lack of correlation found in attitudes among participants with different levels of religiousness.

There was no literature found, which deals with the correlation between education levels and between attitudes towards euthanasia. The findings that academic and nonacademic were significant different in attitudes towards euthanasia, may indicate that professional education has a decisive influence on the process of attitudes shaping. From a research concerning the moral discretion of nurses it may be seen that nurses having a higher level of education have a higher level of moral discretion too [31].

According to the theory of reasoned action of Fishbein \& Ajzen [12] an attitude is the product of a belief representing the information that the individual has in his hands. This belief is a result of information processing which designs the individual's attitudes. Therefore more information about a particular issue may bring about a change of a particular attitude or belief. It is likely that an educated nurse would have more knowledge, and would participate in more study days and professional courses, and would also be updated at the recent innovations. Moreover, an educated nurse would have a broaden horizon. The issue of euthanasia and the right to die in dignity had been attracting much attention and in the recent years, and is being often raised not only among professional circles but also in the media, in the light of the going into effect of the law "the dying patient". Maybe the less educated nurses did not learn the patient's rights law and the ethic code as well in the framework of their studies, and did not fully internalize it in contrast to their counterparts the more educated nurses.

The more nurses' attitudes towards euthanasia of young patients are positive the more positive their behavioral intention would be and vice versa. Similarly, there was a significant positive correlation found between nurses' attitudes towards euthanasia of old people and their behavioral intention towards it. There was no literature found concerning the correlation between attitudes and behavioral intention - both being conditioned by age. It was found that the respondents' attitudes towards euthanasia of old people were more positive in comparison with the attitudes towards euthanasia of their counterparts the young people. Moreover the behavioral intention was more positive as the patient was older.

In the literature there were few researches found. So that when the patients were in similar health condition, nurses and physicians alike believed that more life prolonging treatments are needed to those patients, but that less of them - when the patients were old [32,33]. The reason for these differences may stem from the fact that naturally it is easier to cope with the death of an older patient than the death of a younger one disregarding the kind of the disease they suffer from. The death of young people breaks the natural course of life and thus raises strong feelings of anger, anxiety and failure.

The hypothesis that there would be a correlation between attitudes and behavioral intention conditioned by the different kinds of diseases from which the patients suffer was supported. These findings correspond with a single research being found in the literature [26]. There were no other re- searches found in which the aforementioned correlations were tested. Moreover in a research by Ben-Shachar [34], it was found that nurses' attitudes towards euthanasia were influenced by the kind of ward, which they were working in. Nurses in wards, in which the patients were in a critical condition or were dying and nurses in the children wards tended to hold more positive attitudes towards euthanasia than nurses working in wards in which there were mixed patients with different kinds of diseases. In the present research nurses working in the internal medicine ward and in surgical wards were tested. In these wards mixed treatments of chronic dying patients are given as well as treatments to patients in acute conditions. The influence of the kind of ward in which the nurses were working on their attitudes towards euthanasia was not tested.

The hypothesis that there is a correlation between attitude and behavioral intention with different levels of patient and caregiver relationships was supported. Our findings correspond with other findings of researches found in the literature. Several researches found that when there was previous relationship with the patient, more nurses supported the physician assisted dying (PAD) and more of them were ready to participate in it and attend it when the dying was assisted. They also were more ready to stay with the patient at the time of his death $[7,20]$.

The present research found that there was a significant difference found between attitudes towards euthanasia of a patient with whom there was a long-term relationship, in contrast to a patient with whom there was short-term relationship. Attitudes towards euthanasia were strengthen on by long-term relationship in comparison with short-term relationship, because the nurse knew the patient and was aware of his wishes, and maybe even found it difficult to see him suffering. These findings correspond with the findings of the aforementioned literature.

It was found that there is a positive correlation between attitudes towards euthanasia and behavioral intention. Attitudes towards euthanasia may predict 62 per cent of the behavioral intention in total. This finding corresponds with the theory of reasoned act of Fishbein \& Ajzen [12].

In the literature, which concerns euthanasia there were many contradictory findings [26], On the one hand, there were researches, which demonstrated a correlation between euthanasia and behavioral intention, and on the other hand, there were researches, which showed a gap between attitudes towards euthanasia and behavioral intention $[19,27]$. In many various researches, which were carried out among health workers the findings that were found were similar to those of the present research [35-39].

\section{CONCLUSIONS}

Nurses of today encounter ethical dilemmas similar to those being tackled by physicians, and they also encounter problems stemming from the fact that they obliged to obey the medical instructions imposed on them [29].

According to the literature it seems as if nurses' role has only a small weight in the important process of decisionmaking as long as terminally ill patients are concerned. But albeit nurses' lack of authority to make decisions as to the 
treatment, they have a central role in providing care to the dying patient. Sometimes nurses function as patient's defender, as they stand up for the patient's right to take part in the decision-making process as long as it concerns the treatment [33].

As difficult as the dilemma of life prolonging might be seen, the dilemma of active euthanasia is much difficult. According to the research and to subjects' responses, it seems that dealing with the active euthanasia raises many moral questions, inconvenience and anger too. Is it, that on the basis of the positive attitudes towards euthanasia and the positive behavioral intention, nurses would actually and actively participate in it?

In order to distribute the burden and get as much as objective responses as possible in the issue of continuing a treatment of terminally ill patients, it is necessary to emphasize the importance of the participation of the professional staff, including not only the physicians, but also the nurses who directly supply the prolonging life treatment to patients [40].

The medical education today is directed, on the one hand, towards life protection and life sacredness, and on the other hand it is directed towards respecting the patients' autonomy and right to decide on matters concerning their body and life. Also they have a right to refuse treatment. The dilemma between respecting patient's wish and right to decide on matters of life or death, on the one hand, and between protecting his life, on the other hand continuous to be difficult, and in most cases is an unresolved problem. Repeating coping with the dilemma and researches on the said issue may bring about a higher awareness of it, and may lead also to solutions that would supply the patients' demands as well as the demands of their family members and the professional staff.

\section{REFERENCES}

[1] Leiser RJ, Mitchell TF, Hahn JA, Abrams DI. The role of critical care nurse's in euthanasia and assisted suicide. N Engl J Med 1996; 335(1): 972-4.

[2] Asch DA. The Role of critical care Nurse's in Euthanasia and assisted suicide. N Engl J Med 1996; 334(21): 1374-79.

[3] Steinberg A. "The dying patient - a comparative view on the democratic values and the values of the Jewish religious law (Halacha)". In Cohen-Almagor R, Ed. Ethical dilemmas in medicine. Jerusalem: Van Leer foundation, Hakibutz HaMeuhad publishing. 2002B. p. 283 [Hebrew].

[4] Doukas DJ, Waterhouse D, Gorenflo DW, et al. Attitude and behaviors on physician-assisted death: A study of Michigan oncologists. J Clin Oncol 1995; 3: 1055-61.

[5] Portenoy RK, Coyle N, Kash KM, et al. Determinants of the willingness to endorse assisted suicide: a survey of physicians, nurses and social workers. Psychosomatics 1997; 38(3): 277-87.

[6] Davis AJ, Davidson B, Hirschfield M, et al. An international perspective of active euthanasia: attitudes of nurses in seven countries. Int J Nurs Stud 1993; 30: 301-10.

[7] Young A, Volker D, Rieger PT, et al. Oncology nurses attitudes regarding voluntary, physician assisted dying for competent, terminally ill patients. Oncol Nurs Forum 1993; 20 (3): 445-51.

[8] Daniels CS. The Jewish religious laws (Halacha) and the dying patient, Tmicha - the bulletin of the Israeli institute to treatment supporting 1997; 8: 2-4 [Hebrew].

[9] Fishbein M, Ajzen I. Belief, attitude, intention and behavior: an introduction to theory and research. Reading, M A: AddisionWesley 1975.
[10] Henderson V. The essence of nursing. Tel Aviv, the library of nurses, Am Oved, 1973 [Hebrew].

[11] Gootman A. "The ethics of care giving professions". Dyonon publishing, Tel-Aviv University, 2001 [Hebrew].

[12] Ajzen I, Fishbein M. Understanding attitudes and predicting social behavior. Englwood Cliffs, N.J: Prentice-Hall 1980.

[13] Savage TA, Cullen DZ, Kirchhoff KT, et al. Nurses responses to do not resuscitate order in the neonatal intensive care unit. Nurs Res 1987; 6(36): 370-3.

[14] Yishai R. From the right to die to it's assisting. Medicine 1993; 124(I): 52-5 [Hebrew].

[15] Steinberg A. Medical ethics - directions, access and goals. Medicine 1986; 111 (5-6): 144-6.

[16] Kerridge HI, Kenneth RM. The legislation of active voluntary euthanasia in Australia: will the slippery slope prove fatal? J Med Ethics 1996; 22: 273-8.

[17] Steinberg A. The public committee to the affairs of a dying patient - a bill: the dying patient. Med Law 2002A; 26: 62-78 [Hebrew].

[18] Kushe H, Singer P. Voluntary euthanasia and the nurse: An Australian survey. Int J Nurs Stud 1993; 30(4): 311 -22.

[19] Tanida N, Asai A, Ohnishi M, et al. Voluntary active euthanasia and the nurse: a comparison of Japanese and Australian nurses. Nurs Ethics 2002; 9(3): 13-322.

[20] Musgrave CF, Margalith I, Goldsmidt L. Israeli oncology and nononcology nurses attitudes toward physician assisted dying: A comparison Study. Oncol Nurs Forum 2001; 28(1): 50-7.

[21] Carmel S. Mercy killing and euthanasia: attitudes, wishes and the behavior of the public, patients and physicians. Medicine 2002; 141 (VI): 538-43 [Hebrew].

[22] Carmel S. Medical student's attitudes regarding the use of life sustaining treatments for themselves and elderly persons. Soc Sci Med 1998; 46(4-5): 467-74.

[23] Gow CM, Williams JI. Nurses attitudes toward death and dying: A causal interpretation. Soc Sci Med 1977; 11: 191-8.

[24] Tomer A, Elisason G. Toward A comprehensive model of death anxiety. Death Stud 1996; 20: 343-65.

[25] Kowalski SD. Nevada nurses attitudes regarding physician assisted suicide. CNS 1997; 11(3): 109-15.

[26] Davis AJ, Phillips L, Drought TS, et al. Nurses attitudes toward active euthanasia. Nurs Outlook 1995; 43(4): 174-9.

[27] Richardson DS. Oncology nurses attitudes toward the legalization of voluntary active euthanasia. Cancer Nurs 1994; 17(4): 348-54.

[28] Carmel S, Mutran E. Wishes regarding the use of life sustaining treatments among elderly persons in Israel: An explanatory model. Soc Sci Med 1997: 45(11): 1715-27.

[29] Zeidenberg C. Nurses' attitudes towards prolonging the life of terminally ill patients. [A master's thesis] medical science, Ben-Gurion University of the Negev 1997 [Hebrew].

[30] James GA, David PC. Attitudes of medical professionals towards euthanasia. Soc Sci Med 1993; 37(1): 105-14.

[31] Duckett L, Rowan-Boyer M, Ryden MB, et al. Challenging misperceptions about nurses' moral reasoning. Nurs Res 1992; 41: 324-31.

[32] Carmel S. Behavior, attitudes and expectations regarding the use of life sustaining treatments among physicians in Israel: an exploratory study. Soc Sci Med 1996; 43(6): 955-65.

[33] Carmel S, Zeidenberg H. Nurse's attitudes toward end of middle aged and old terminally ill patients. In: Tomer A (Ed) Death attitudes and the older adults: theories, concepts and applications. New York: Brunner/Mazel 2000; 193-210.

[34] Ben-Shachar V. Nurses' attitudes towards euthanasia and the factors influencing it. [a master's thesis], faculty of law: Tel-Aviv University 1980; [Hebrew].

[35] Laschinger SHK, Goldenberg D. Attitudes of practicing nurses as predictors of intended care behavior with persons who are HIV positive: testing the Ajen-Fishbein theory of reasoned action. Res Nurs Health 1993; 16: 441-50.

[36] Mckinlay A, Couston M, Cowan S. Nurses behavioral intentions towards self poisoning patients: a theory of reasoned action, comparison of attitudes, and subjective norms as a predictive variables. J Adv Nurs 2001; 34 (1): 107-16. 
[37] Werner P, Mendelsson G. Nursing Staff members intentions to use physical restraints with old people: testing the theory of reasoned action. J Adv Nurs 2001; 35(5): 584-91.

[38] Maragel A. Attitudes and behavioral intentions of community nurses towards reporting on child abuse. a term paper for Master degree in nursing. Department of nursing: Tel-Aviv University 2001 [Hebrew].
[39] Ozon M. The influence of attitudes, subjective norms and the perceived behavioral control of nurses on protecting patient's privacy in hospital. a term paper for a Master degree in nursing. Department of nursing: Tel-Aviv University 2002 [Hebrew].

[40] Steinberg A. Decision - Making and the role of surgery in withdrawal or withholding of therapy in neonates. Clin Perineotol 1998; 25: 779-90.

(C) Penn and Tabak; Licensee Bentham Open.

This is an open access article licensed under the terms of the Creative Commons Attribution Non-Commercial License (http://creativecommons.org/licenses/by$\mathrm{nc} / 3.0 /$ ) which permits unrestricted, non-commercial use, distribution and reproduction in any medium, provided the work is properly cited. 